\title{
Phase Relationships and Physical Properties of Homologous Compounds in the Zinc Oxide-Indium Oxide System
}

\author{
Toshihiro Moriga, ${ }^{*},+$ Doreen D. Edwards, ${ }^{*}$ and Thomas O. Mason ${ }^{*}$ \\ Department of Materials Science and Engineering and Materials Research Center, Northwestern University, \\ Evanston, Illinois 60208-3108
}

George B. Palmer and Kenneth R. Poeppelmeier ${ }^{*}$ Department of Chemistry and Materials Research Center, Northwestern University, Evanston, Illinois 60208-3113

Jon L. Schindler ${ }^{\ddagger}$ and Carl R. Kannewurf

Department of Electrical and Computer Engineering, Northwestern University, Evanston, Illinois 60208-3118

Ichiro Nakabayashi

Department of Chemical Science and Technology, Faculty of Engineering, Tokushima University, Tokushima 770, Japan

\begin{abstract}
Equilibrium phase relationships in the $\mathrm{ZnO}-\mathrm{In}_{2} \mathrm{O}_{3}$ system were determined between $1100^{\circ}$ and $1400^{\circ} \mathrm{C}$ using solidstate reaction techniques and $\mathrm{X}$-ray diffractometry. In addition to $\mathrm{ZnO}$ and $\mathrm{In}_{2} \mathrm{O}_{3}$, nine homologous compounds, $\mathrm{Zn}_{k} \operatorname{In}_{2} \mathrm{O}_{k+3}$ (where $k=3,4,5,6,7,9,11,13$, and 15), were observed. Electrical conductivity and diffuse reflectance of the $k=3,4,5,7$ and 11 members were measured before and after annealing at $400^{\circ} \mathrm{C}$ for $1 \mathrm{~h}$ under forming gas $(4 \%$ $\mathrm{H}_{2}-\mathbf{9 6} \% \mathrm{~N}_{2}$ ). Room-temperature conductivity increased as $\boldsymbol{k}$ decreased, because of increased carrier concentration as well as increased mobility. In general, transparency in the wavelength range of $450-900 \mathrm{~nm}$ increased as $k$ increased. Reduction in forming gas resulted in increased conductivity and reduced transparency for all compounds measured. The highest room-temperature conductivity measured, 270 $\mathrm{S} / \mathrm{cm}$, was that of reduced $\mathrm{Zn}_{3} \operatorname{In}_{2} \mathrm{O}_{6}$.
\end{abstract}

\section{Introduction}

$\mathrm{T}$ RANSPARENT conducting oxides, or TCOs, are widely used as transparent electrodes for flat panel displays and solar cells. Commercial, thin-film tin-doped indium oxide, or ITO, exhibits a conductivity of 1000-5000 S/cm and an optical transparency of $85 \%-90 \% .{ }^{1}$ Nevertheless, alternative materials with higher conductivity, better transparency at blue-green wavelengths, and lower cost are desired. There have been several recent reports of thin-film TCOs in the $\mathrm{ZnO}-\mathrm{In}_{2} \mathrm{O}_{3}$ system,

N. J. Dudney — contributing editor

\footnotetext{
Manuscript No. 191148. Received March 11, 1997; approved July 15, 1997.

Supported by the MRSEC Program of the National Science Foundation (under Contract No. DMR-9632472) at the Materials Research Center of Northwestern University. This work made use of the Central Facilities, which were also supported by the same MRSEC program. Author TM, on sabbatical at Northwestern University during the time of the study, was supported by a Research Fellowship from the Ministry of Education of Japan. Author GBP was supported by a National Defense Science and Engineering Graduate Fellowship from the U.S. Office of Naval Research.

${ }^{\star}$ Member, American Ceramic Society.

${ }^{\dagger}$ Permanent address: Department of Chemical Society and Technology, Faculty of Engineering, Tokushima University, Tokushima 770, Japan.

Permanent address: CMRC-Display Technologies Group, Motorola, Schaumburg, IL 60196 .
}

demonstrating that high transparency and high conductivity can be achieved for a wide range of film compositions. Wang et $a{ }^{2}{ }^{2}$ reported conductivities as high as $1100 \mathrm{~S} / \mathrm{cm}$ for sputtered $\mathrm{ZnO}$ films containing $<5$ at.\% indium. ${ }^{2}$ Minami and coworkers $^{3,4}$ reported conductivities as high as $2900 \mathrm{~S} / \mathrm{cm}$ for $\mathrm{Zn}_{2} \mathrm{In}_{2} \mathrm{O}_{5}$ films sputtered from polycrystalline targets containing 10-60 at.\% zinc. In studies of pulse-laser-deposited tindoped films, Phillips et al. ${ }^{5}$ reported conductivities as high as $2500 \mathrm{~S} / \mathrm{cm}$ for films with a $[\mathrm{Zn}]:([\mathrm{In}]+[\mathrm{Sn}])$ ratio of $0.5-0.6$.

Although nonequilibrium conditions often exist during thinfilm deposition, knowledge of equilibrium phase relationships and bulk, physical properties of stable phases can be helpful in interpreting and directing thin-film work. Although it is well documented that $\mathrm{ZnO}$ and $\mathrm{In}_{2} \mathrm{O}_{3}$ react to form several stable compounds, a complete phase diagram of the $\mathrm{ZnO}-\mathrm{In}_{2} \mathrm{O}_{3}$ system has not been reported. Furthermore, there are few reports regarding the electrical and optical properties of $\mathrm{ZnO}-\mathrm{In}_{2} \mathrm{O}_{3}$ phases. In this study, we present the $\mathrm{ZnO}-\mathrm{In}_{2} \mathrm{O}_{3}$ phase diagram for $1100^{\circ}-1400^{\circ} \mathrm{C}$. We also characterize the electrical and optical properties of five $\mathrm{ZnO}-\mathrm{In}_{2} \mathrm{O}_{3}$ phases to investigate the compositional dependency of properties important for TCO applications.

$\mathrm{ZnO}$ and $\mathrm{In}_{2} \mathrm{O}_{3}$ react at high temperatures $\left(>1000^{\circ} \mathrm{C}\right)$ to form a series of homologous compounds, $\mathrm{Zn}_{k} \mathrm{In}_{2} \mathrm{O}_{k+3}$, where $k$ is an integer. Kasper $^{6}$ demonstrated the formation of $k=2-5$ and 7 members at $1100^{\circ}-1550^{\circ} \mathrm{C}$ but could not obtain the spinel $(k=$ $1)$, even at temperatures as high as $1750^{\circ} \mathrm{C}$. Nakamura et al. ${ }^{7}$ reported that $\mathrm{Zn}_{k} \operatorname{In}_{2} \mathrm{O}_{k+3}(k=3,4,5,6,7,8,9,11,13$, and 15) are stable at $1350^{\circ} \mathrm{C}$ and that $\mathrm{Zn}_{k} \mathrm{In}_{2} \mathrm{O}_{k+3}(k=20)$ forms at $1550^{\circ} \mathrm{C}$. They also speculated that an infinite number of phases could exist between the $k=20$ member and ZnO. Kimizuka et $\mathrm{al}^{8}{ }^{8}$ reported the formation of $k=3-5,7,9$, and 11 members at $1150^{\circ}-1550^{\circ} \mathrm{C}$. The temperature range of stability of most of the $\mathrm{Zn}_{k} \mathrm{In}_{2} \mathrm{O}_{k+3}$ members has not been reported.

$\mathrm{ZnO}$ crystallizes in the hexagonal wurtzite structure with $a=3.2498 \AA$ and $c=5.2066 \AA$ (JCPDS $^{\S}$ Card No. 36-1451). $\mathrm{In}_{2} \mathrm{O}_{3}$ crystallizes in the $\mathrm{C}-\mathrm{M}_{2} \mathrm{O}_{3}$ (bixbyite) structure with $a=$ $10.117 \AA$ (JCPDS Card No. 6-416). The homologous $\mathrm{Zn}_{k} \mathrm{In}_{2} \mathrm{O}_{k+3}$ compounds crystallize in $R-3 m$, for odd $k$ values with $z=3$, and in $P 6_{3} / m m c$, for even $k$ values with $z=2$

\footnotetext{
§ Joint Committee on Powder Diffraction Standards, Swarthmore, PA (now Inter-
} national Centre for Diffraction Data (ICDD), Newtowne Square, PA). 
(where $z$ is the number of formula units per unit cell). The structures are characterized by a short $\boldsymbol{a}$-axis (3.2-3.4 $\AA$ ) and a long $c$-axis (e.g., $42.5 \AA$ for $k=3$ and $33.5 \AA$ for $k=4$ ). Based on high-resolution electron microscopy results, Cannard and Tilley ${ }^{9}$ proposed that the structures consist of $k \mathrm{ZnO}$ layers separated by two $\mathrm{InO}_{1.5}$ layers, arranged such that $[001]_{\mathrm{ZnO}}$ and $[111]_{\mathrm{In}_{2} \mathrm{O}_{3}}$ are parallel to [001] of the $\mathrm{Zn}_{k} \mathrm{In}_{2} \mathrm{O}_{k+3}$ structures. More recently, Nakamura et al. $^{7}$ and Kimizuka et al. ${ }^{8}$ suggested that the compounds are isostructural with $\mathrm{LuFeO}_{3}(\mathrm{ZnO})_{k}$. Although the two models are not identical, both feature wurtzite-type layers perpendicular to the $c$-axis of the $\mathrm{Zn}_{k} \mathrm{In}_{2} \mathrm{O}_{k+3}$ structures.

$\mathrm{ZnO}$ and $\mathrm{In}_{2} \mathrm{O}_{3}$ exhibit $n$-type semiconductivity. For $\mathrm{ZnO}$ and indium-doped $\mathrm{ZnO}$ powders, Wang et al. ${ }^{10}$ reported conductivities ranging from 0.0001 to $30 \mathrm{~S} / \mathrm{cm}$. Ohta et al. ${ }^{11}$ reported that $\mathrm{Zn}_{k} \operatorname{In}_{2} \mathrm{O}_{k+3}(k=5,7$, and 9) are also $n$-type semiconductors, with conductivities on the order of 100-300 $\mathrm{S} / \mathrm{cm}$ at $227^{\circ}-727^{\circ} \mathrm{C}$. Phillips et al. ${ }^{5}$ reported a room-temperature conductivity of $\sim 550 \mathrm{~S} / \mathrm{cm}$ for bulk, reduced $\mathrm{Zn}_{3} \mathrm{In}_{1.975} \mathrm{Sn}_{0.025} \mathrm{O}_{6}$.

\section{Experimental Procedure}

A series of compositions were prepared from $\operatorname{In}_{2} \mathrm{O}_{3}$ and $\mathrm{ZnO}$ powders ( $>99.9 \%$ purity, on a cation basis, Aldrich Chemical Co., Milwaukee, WI). Weighed amounts of the dried starting powders were ground together with a mortar and pestle, to provide a series of samples with integral $\mathrm{Zn}$ :In ratios ranging from 1 to 15 . The mixed powder was calcined at $1000^{\circ} \mathrm{C}$ overnight in air and then reground. Pellets pressed from this powder were heated in covered high-density alumina crucibles. The grinding and heating steps were repeated as necessary to attain equilibrium, as determined by X-ray diffractometry (XRD). The total heating times were $7-10$ days at $\leq 1100^{\circ} \mathrm{C}, 7$ days at $1101^{\circ}-1249^{\circ} \mathrm{C}, 5$ days at $1250^{\circ} \mathrm{C}, 4$ days at $1251^{\circ}-1300^{\circ} \mathrm{C}$, and 3-4 days at $\geq 1300^{\circ} \mathrm{C}$. Each pellet was sandwiched between sacrificial pellets or surrounded by powder of the same composition, to minimize contamination from the alumina crucible and to inhibit vaporization of $\mathrm{ZnO}$ during firing. Weight loss during firing was typically $<0.8 \%$. After heating at the desired temperature, the samples were removed from the furnace at temperature and cooled in ambient air, resulting in room-temperature pellets in $\sim 20 \mathrm{~min}$. The phase composition was determined by powder XRD (Scintag, Santa Clara, CA) using $\mathrm{Cu} K \alpha$ radiation $(40 \mathrm{kV}, 20 \mathrm{~mA})$. Commercial software (Scintag) was used to remove the background and $\mathrm{CuK \alpha} \alpha_{2}$ contributions from the diffraction patterns.

Electrical conductivity and diffuse reflectance of sintered pellets were measured before and after reduction in forming gas $\left(4 \% \mathrm{H}_{2}-96 \% \mathrm{~N}_{2}\right)$ at $400^{\circ} \mathrm{C}$ for $1 \mathrm{~h}$. The $\mathrm{Zn}_{k} \mathrm{In}_{2} \mathrm{O}_{k+3}$ pellets used for these tests were reacted/sintered at $1400^{\circ} \mathrm{C}$ and had relative densities near $50 \%$ of theoretical. For comparison to the homologous compounds, $\mathrm{ZnO}$ and $\mathrm{In}_{2} \mathrm{O}_{3}$ pellets were also examined. The $\mathrm{In}_{2} \mathrm{O}_{3}$, sintered at $1400^{\circ} \mathrm{C}$, was similar to the homologous compounds, in terms of density and color. $\mathrm{ZnO}$ sintered at $1400^{\circ} \mathrm{C}$ was black, indicating severe reduction, and had a density that was $>95 \%$ of the theoretical density. Sinter-

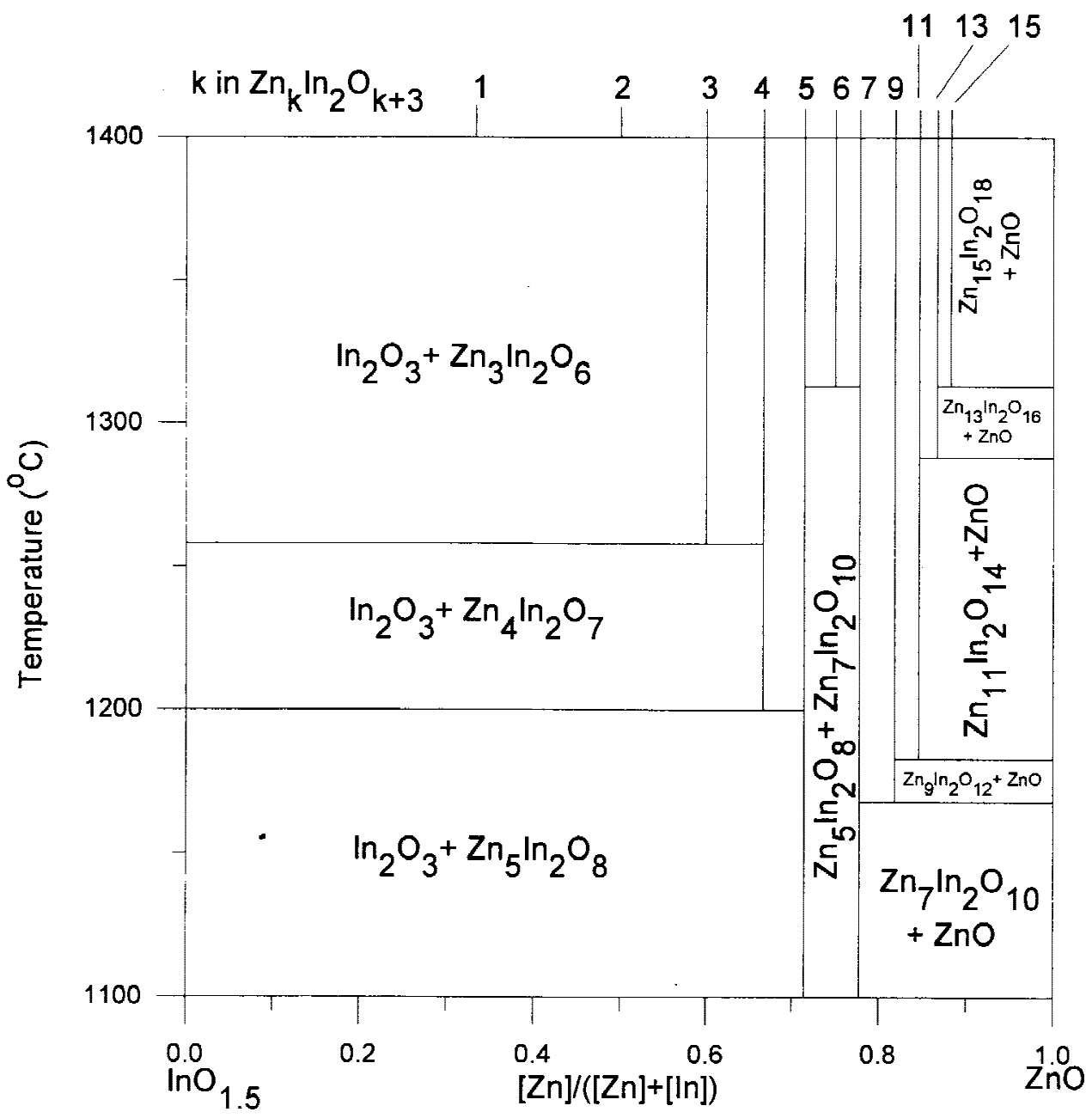

Fig. 1. Phase diagram for the $\mathrm{In}_{2} \mathrm{O}_{3}-\mathrm{ZnO}$ system over the temperature range of $1100^{\circ}-1400^{\circ} \mathrm{C}$. 
Table I. Phase Analysis of Prepared Compositions

\begin{tabular}{|c|c|c|c|c|c|c|c|c|c|c|c|c|c|c|}
\hline \multirow{2}{*}{$\begin{array}{c}\text { Indium } \\
\text { concentration, } \\
{[\operatorname{In}]}\end{array}$} & \multicolumn{14}{|c|}{ Reaction temperature $\left({ }^{\circ} \mathrm{C}\right)^{\dagger}$} \\
\hline & 1100 & 1150 & 1160 & 1175 & 1190 & 1200 & 1215 & 1250 & 1265 & 1275 & 1300 & 1325 & 1350 & 1400 \\
\hline 0.02 & $0+5$ & & & & & $0+4$ & & & & & $0+3$ & & & $0+3$ \\
\hline 0.20 & $0+5$ & $0+5$ & & & $0+5$ & $0+4$ & $0+4$ & $0+4$ & $0+3$ & & $0+3$ & & $0+3$ & $0+3$ \\
\hline 0.33 & $0+5$ & $0+5$ & & & $0+5$ & $0+4$ & $0+4$ & $0+4$ & $0+3$ & & $0+3$ & & $0+3$ & $0+3$ \\
\hline 0.50 & $0+5$ & $0+5$ & & & $0+5$ & $0+4$ & $0+4$ & $0+4$ & $0+3$ & & $0+3$ & & $0+3$ & $0+3$ \\
\hline 0.60 & $0+5$ & $0+5$ & & & $0+5$ & $0+4$ & $0+4$ & $0+4$ & 3 & & 3 & & 3 & 3 \\
\hline 0.63 & $0+5$ & & & & & $0+4$ & $0+4$ & $0+4$ & $3+4$ & & $3+4$ & & $3+4$ & $3+4$ \\
\hline 0.67 & $0+5$ & $0+5$ & & & $0+5$ & 4 & 4 & 4 & 4 & & 4 & & 4 & 4 \\
\hline 0.69 & & & & & & $4+5$ & $4+5$ & $4+5$ & $4+5$ & & $4+5$ & & $4+5$ & $4+5$ \\
\hline 0.71 & 5 & 5 & & 5 & 5 & 5 & 5 & 5 & 5 & & 5 & 5 & 5 & 5 \\
\hline 0.73 & & & & & & & & & & & & $5+6$ & & $5+6$ \\
\hline 0.75 & $5+7$ & $5+7$ & & $5+7$ & & $5+7$ & & $5+7$ & & & $5+7$ & & 6 & 6 \\
\hline 0.76 & & & & & & & & & & & & $6+7$ & & $6+7$ \\
\hline 0.78 & 7 & 7 & 7 & 7 & 7 & 7 & & 7 & & & 7 & 7 & 7 & 7 \\
\hline 0.80 & & & & $7+9$ & $7+9$ & $7+9$ & & $7+9$ & & & $7+9$ & $7+9$ & $7+9$ & $7+9$ \\
\hline 0.82 & $7+\infty$ & $7+\infty$ & & 9 & 9 & 9 & & 9 & & 9 & 9 & 9 & 9 & 9 \\
\hline 0.83 & & & $7+\infty$ & & $9+11$ & $9+11$ & & $9+11$ & & $9+11$ & $9+11$ & & $9+11$ & $9+11$ \\
\hline 0.85 & & & & & 11 & 11 & & 11 & & 11 & 11 & 11 & 11 & 11 \\
\hline 0.86 & & & & & & & & & & $11+\infty$ & $11+13$ & & & $11+13$ \\
\hline 0.87 & & & & & $11+\infty$ & $11+\infty$ & & $11+\infty$ & & & 13 & 13 & 13 & 13 \\
\hline 0.875 & & & & & & & & & & & & $13+15$ & & $13+15$ \\
\hline 0.88 & & & & & & $11+\infty$ & & $11+\infty$ & & & $13+\infty$ & 15 & 15 & 15 \\
\hline 0.91 & & & & & & & & & & & & $15+\infty$ & $15+\infty$ & $15+\infty$ \\
\hline 0.95 & $7+\infty$ & $7+\infty$ & $7+\infty$ & $11+\infty$ & $11+\infty$ & $11+\infty$ & & $11+\infty$ & & & $13+\infty$ & $15+\infty$ & $15+\infty$ & $15+\infty$ \\
\hline
\end{tabular}

"Integers greater than zero indicate $k$ in $\mathrm{Zn}_{k} \mathrm{In}_{2} \mathrm{O}_{k+3}$, “ 0 ”, indicates $\mathrm{In}_{2} \mathrm{O}_{3}$, and “ $\infty$ ” indicates $\mathrm{ZnO}$.

ing at $800^{\circ} \mathrm{C}$ for 15 min provided a $\mathrm{ZnO}$ pellet with a relative density similar to that of the homologous compounds.

The room-temperature electrical conductivity was measured with a linear four-point probe using a current source and voltmeter (Models 225 and 197, Keithley Instruments, Cleveland, $\mathrm{OH})$. Excitation currents ranged from $100 \mathrm{nA}$ to $10 \mathrm{~mA}$. The conductivity was calculated as

$$
\sigma=\frac{1}{\rho}=\frac{1}{\frac{V}{I} w C\left(\frac{d}{s}\right) F\left(\frac{w}{s}\right)}
$$

where $\sigma$ is the conductivity, $\rho$ the resistivity, $V$ the voltage, $I$ the current, $w$ the pellet width, $d$ the pellet diameter, and $s$ the electrode spacing; $C(d / s)$ and $F(w / s)$ are correction factors that account for sample geometry and finite thickness, respectively. ${ }^{12}$ The room-temperature Hall effect and conductivity measurements of the reduced $\mathrm{Zn}_{k} \mathrm{In}_{2} \mathrm{O}_{k+3}$ compounds were made on rectangular, bar-shaped samples cut from the reduced pellets. Electrical contacts to the bars were prepared with small indium dots. Gold sample leads (60 or $25 \mu \mathrm{m}$ in diameter) were bonded to the indium contacts with silver paste. The Hall measurements used magnetic flux densities of $\sim 8000 \mathrm{G}(0.8 \mathrm{~T})$ and measurement currents of $0.1-2.0 \mathrm{~mA}$, depending on the sample response. All voltages were measured using a nanovoltmeter (Model 182, Keithley). The conductivity values measured for the bar-shaped samples agreed within $20 \%$ of those determined by the linear four-point probe. To account for the variation in the densities among the measured samples, carrier concentration and conductivity values were divided by the relative density of the corresponding sample. Therefore, the conductivities reported in this paper are roughly 2 times larger than the actual measured values.

Diffuse reflectance was measured from 200 to $900 \mathrm{~nm}$ using a double-beam spectrophotometer with integrating sphere (Model Cary 1E with Cary 1/3 attachment, Varian, Palo Alto, CA). Baseline spectra were collected with pressed polytetrafluoroethylene (PTFE) powder compacts (Varian Part No. 04101439-00) placed in the sample and reference beams. Sample measurements on as-fired and as-annealed pellets, with no further surface preparation, were made in reference to the PTFE standards.

\section{Results and Discussion}

Figure 1 shows the phase diagram of the $\mathrm{ZnO}-\mathrm{In}_{2} \mathrm{O}_{3}$ system, from $1100^{\circ}$ to $1400^{\circ} \mathrm{C}$. The phase diagram is similar to the $\mathrm{Ga}_{2} \mathrm{O}_{3}-\mathrm{TiO}_{2}$ system, which also contains several homologous compounds. ${ }^{13}$ In accordance with the equilibrium phase rule, the diffraction patterns used to construct this diagram showed only one or two phases, as summarized in Table I. In addition to $\mathrm{ZnO}$ and $\mathrm{In}_{2} \mathrm{O}_{3}$, nine homologous compounds, summarized in Table II, were detected. The lower limit of temperature stability $\left(T_{\text {low }}\right)$ (Table II) is given as the midpoint between the lowest firing temperatures at which the corresponding compound was observed and the highest firing temperature at which the corresponding compound did not form. The large uncertainty shown for $T_{\text {low }}$ in Table II results from the temperature intervals used in this study, typically $15^{\circ}-25^{\circ} \mathrm{C}$. To confirm that the small number of compounds observed at the lowest temperatures was not due to kinetic limitations of the $\mathrm{In}_{2} \mathrm{O}_{3}-\mathrm{ZnO}$ reaction, $\mathrm{Zn}_{3} \mathrm{In}_{2} \mathrm{O}_{6}$ samples were annealed at $1100^{\circ}$ and $1250^{\circ} \mathrm{C}$, for 3 weeks and 1 week, respectively, resulting in partial decomposition, which is consistent with the phase relationships shown in Fig. 1.

In Fig. 1, line compounds, rather than regions of solid solution, are shown, because the lattice parameters measured for the homologous compounds in the biphasic mixtures were

Table II. Lower Limit of Stability $\left(T_{\text {low }}\right)$ and Lattice Constants of $\mathrm{Zn}_{k} \mathrm{In}_{2} \mathrm{O}_{k+3}$ Compounds

\begin{tabular}{|c|c|c|c|c|}
\hline \multirow{2}{*}{$\begin{array}{l}k \text { value in } \\
\mathrm{Zn}_{k} \mathrm{In}_{2} \mathrm{O}_{k+3}\end{array}$} & \multirow[b]{2}{*}{$T_{\text {low }}\left({ }^{\circ} \mathrm{C}\right)^{\dagger}$} & \multicolumn{2}{|c|}{ Lattice parameter $(\AA)^{\dagger}$} & \multirow{2}{*}{$\begin{array}{c}\text { Normalized } \\
\text { lattice } \\
\text { parameter, } \\
c(\AA) / z\end{array}$} \\
\hline & & $a$ & $c$ & \\
\hline 3 & $1258(8)$ & $3.353(1)$ & $42.50(1)$ & 14.17 \\
\hline 4 & $1200(10)$ & 3.338 (1) & 33.52 (1) & 16.76 \\
\hline 5 & $\leq 1100$ & $3.326(1)$ & $58.10(1)$ & 19.37 \\
\hline 6 & 1313 (13) & $3.316(1)$ & 43.95 (1) & 21.98 \\
\hline 7 & $\leq 1100$ & $3.311(1)$ & $73.68(1)$ & 24.56 \\
\hline 9 & $1168(8)$ & $3.300(1)$ & $89.24(1)$ & 29.75 \\
\hline 11 & $1183(8)$ & $3.291(1)$ & 104.95 (1) & 34.98 \\
\hline 13 & 1288 (13) & $3.284(1)$ & $120.36(1)$ & 40.12 \\
\hline 15 & 1313 (13) & $3.278(1)$ & 135.98 (1) & 45.33 \\
\hline
\end{tabular}

\footnotetext{
"Numbers given in parentheses are estimated uncertainties.
} 


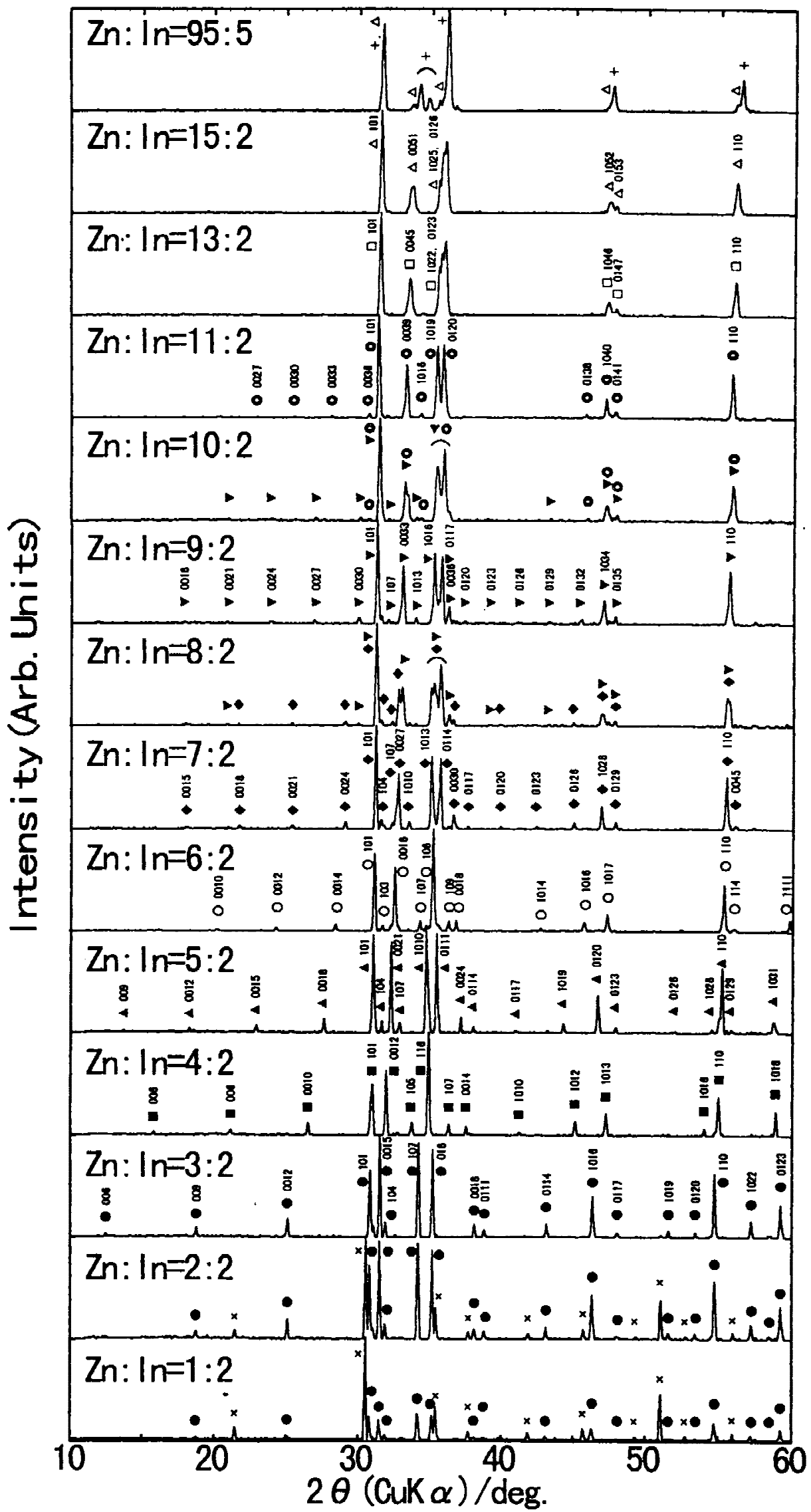

Fig. 2. X-ray diffractograms for $\mathrm{ZnO}-\mathrm{In}_{2} \mathrm{O}_{3}$ compositions reacted at $1400^{\circ} \mathrm{C}$. Peaks are indexed as $(h k l)$ or $(h k l l)\left((\times) \mathrm{In}_{2} \mathrm{O}_{3},(\boldsymbol{\bullet}) \mathrm{Zn}_{3} \mathrm{In}_{2} \mathrm{O}_{6}\right.$, $(\boldsymbol{\square})$

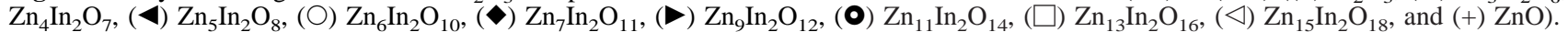




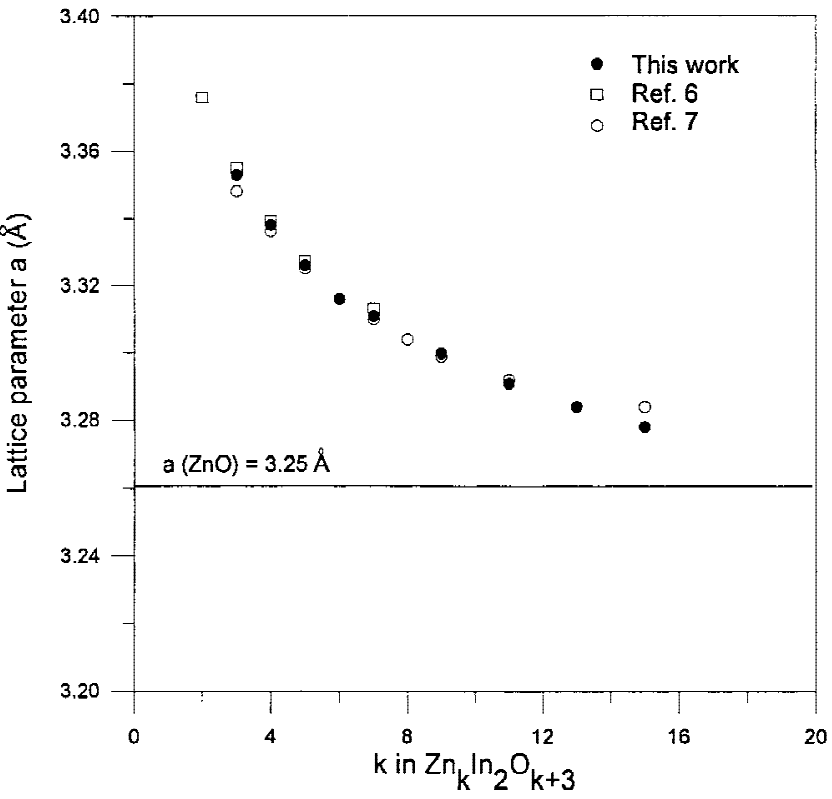

Fig. 3. Lattice constant $a$, as a function of $k$ in $\mathrm{Zn}_{k} \operatorname{In}_{2} \mathrm{O}_{k+3}$.

identical, within experimental uncertainty, to those of the corresponding single-phase materials. Wang et al. ${ }^{10}$ reported that up to 0.45 at.\% indium is incorporated in $\mathrm{ZnO}$ processed at $1200^{\circ} \mathrm{C}$. Considering the structural similarity between the homologous compounds and $\mathrm{ZnO}$, we recognize that narrow regions of solid solution may exist.

The diagram shown in Fig. 1 is in disagreement with the conclusions drawn by Nakamura et al., ${ }^{7}$ who reported that $\mathrm{Zn}_{8} \mathrm{In}_{2} \mathrm{O}_{11}$ and possibly $\mathrm{Zn}_{10} \mathrm{In}_{2} \mathrm{O}_{13}$ are stable phases at $1350^{\circ} \mathrm{C}$. Figure 2 shows the XRD patterns obtained for compositions heated at $1400^{\circ} \mathrm{C}$. For higher-order members of the series, the peak overlap in the interval $32^{\circ} \leq 2 \theta \leq 40^{\circ}$ makes it somewhat difficult to distinguish between successive members of the homologous series. Nevertheless, from the X-ray patterns, we are confident that the sample prepared with a $\mathrm{Zn}$ :In ratio of 8:2 consists of $\mathrm{Zn}_{7} \mathrm{In}_{2} \mathrm{O}_{10}$ and $\mathrm{Zn}_{9} \mathrm{In}_{2} \mathrm{O}_{12}$ and that the sample prepared with a $\mathrm{Zn}: \mathrm{In}$ ratio of $10: 2$ consists of $\mathrm{Zn}_{9} \mathrm{In}_{2} \mathrm{O}_{12}$ and $\mathrm{Zn}_{11} \mathrm{In}_{2} \mathrm{O}_{14}$. Although the diffraction pattern of the sample prepared with a $\mathrm{Zn}$ :In ratio of $95: 5(k=38)$ is consistent with a biphasic mixture of $\mathrm{ZnO}$ and $\mathrm{Zn}_{15} \mathrm{In}_{2} \mathrm{O}_{18}$, the presence of higher-order members of the $\mathrm{Zn}_{k} \mathrm{In}_{2} \mathrm{O}_{k+3}$ series would be almost impossible to detect with the XRD technique used in this study. Therefore, additional homologous members with $k>15$ may be stable at this temperature.

The lattice constants determined in this study, also summarized in Table II, agree well with values reported in the literature. ${ }^{6-8}$ Figure 3 shows that the lattice parameter $a$ decreases as $k$ increases, from $a=3.353 \AA$ for $k=2$ to a value approaching that of wurtzite-type $\mathrm{ZnO}(a=3.250 \AA)$. This trend reflects the increasing influence of the $\mathrm{ZnO}$ layers in defining the $\boldsymbol{a}$-axis of the homologous compounds. To make meaningful comparisons among members of the homologous series, the lattice parameter $c$ is divided by the number of formula units per unit cell $(z)$. Figure 4 shows that the normalized lattice parameter, $c / z$, increases linearly as $k$ increases, at a rate of 2.6 $\AA / k$, which corresponds to one-half of the lattice constant $c$ of $\mathrm{ZnO}$, i.e., one $\mathrm{Zn}-\mathrm{O}$ layer.

The color of the $\mathrm{Zn}_{k} \mathrm{In}_{2} \mathrm{O}_{k+3}$ compounds fired at $1400^{\circ} \mathrm{C}$ ranged from dark yellow-green to light canary yellow with increasing zinc content. The samples calcined at $1100^{\circ} \mathrm{C}$ were generally lighter than higher-temperature samples, with colors ranging from dark to light yellow with increasing zinc content. Figure 5 shows the diffuse reflectance spectra of $\mathrm{Zn}_{k} \operatorname{In}_{2} \mathrm{O}_{k+3}$ $(k=3,4,5,7$, and 11$)$ prepared at $1400^{\circ} \mathrm{C}$ before and after reduction. Diffuse reflectance spectra of bulk samples are

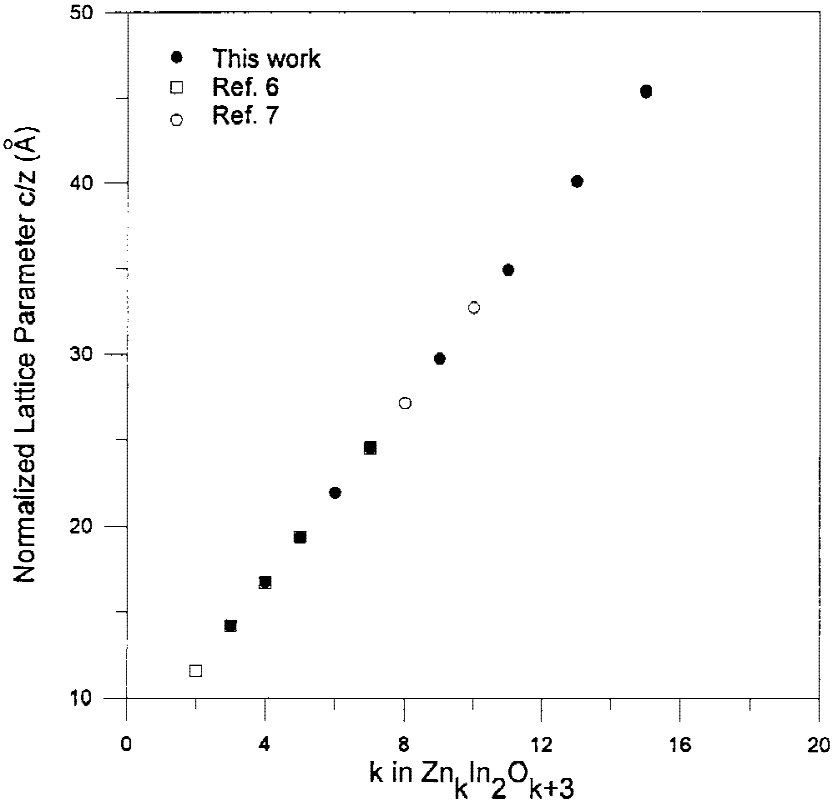

Fig. 4. Normalized lattice constant $(c / z)$, as function of $k$ in $\mathrm{Zn}_{k} \mathrm{In}_{2} \mathrm{O}_{k+3}$.

analogous to transmission spectra of thin samples. ${ }^{14}$ All samples exhibit a transition from absorbing behavior at $\lambda<400$ $\mathrm{nm}$ to transmitting (reflecting) behavior at $\lambda>450 \mathrm{~nm}$. Based on the onset of diffuse reflection, the band gaps of $\mathrm{Zn}_{k} \mathrm{In}_{2} \mathrm{O}_{k+3}$ $(k=3,4,5,7$, and 11) are estimated to be $2.8-3.0 \mathrm{eV}$, which is in good agreement with a value of $2.9 \mathrm{eV}$ reported for $\mathrm{Zn}_{2} \mathrm{In}_{2} \mathrm{O}_{5} \cdot{ }^{3,4}$ Table III shows that the absorption edge decreases, or the band gap increases, as $k$ increases. Reduction in forming gas results in an increase in the band gap. This phenomenon, known as the Burstein-Moss shift, has been observed in many TCO materials and results from increased carrier concentration. ${ }^{15}$ For the as-fired samples, transparency at $\lambda$ $>450 \mathrm{~nm}$ increases as $k$ increases. For each of the compounds, transparency decreases upon reduction in forming gas.

Table III and Fig. 6 show that the electrical conductivity of the $\mathrm{Zn}_{k} \mathrm{In}_{2} \mathrm{O}_{k+3}$ compounds decreases as $k$ increases. Hall effect measurements of the reduced $\mathrm{Zn}_{k} \mathrm{In}_{2} \mathrm{O}_{k+3}$ samples indicate that the decrease in conductivity results from decreased carrier concentration as well as decreased mobility. Reduction in forming gas (low oxygen partial pressure) results in increased conductivity for all the compounds, presumably because of the formation of oxygen vacancies, which serve as electron donors. The effect of reduction on the resulting conductivity increases as $k$ increases for the $\mathrm{Zn}_{k} \operatorname{In}_{2} \mathrm{O}_{k+3}$ compounds. For example, the conductivity of $\mathrm{Zn}_{7} \mathrm{In}_{2} \mathrm{O}_{10}$ increases by more than 2 orders of magnitude on reduction, whereas that of $\mathrm{Zn}_{3} \operatorname{In}_{2} \mathrm{O}_{6}$ is only doubled.

Examination of the similarities and differences among the homologous compounds and parent oxides is the first step toward understanding the defect chemistry of the $\mathrm{Zn}_{k} \operatorname{In}_{2} \mathrm{O}_{k+3}$ materials. Based on the layered structural models proposed for the homologous compounds, we anticipated that the electrical properties would be intermediate between that of $\operatorname{In}_{2} \mathrm{O}_{3}$ and $\mathrm{ZnO}$, approaching those of $\mathrm{ZnO}$ with increasing $k$; however, this was not strictly the case. The lowest-order member examined in this work, $\mathrm{Zn}_{3} \operatorname{In}_{2} \mathrm{O}_{6}(k=3)$, is similar to $\operatorname{In}_{2} \mathrm{O}_{3}(k=$ $0)$, in terms of color and conductivity before and after reduction in forming gas (see Fig. 6). In the oxidized state, the colors of the homologous compounds become lighter with increasing $k$, a trend that is consistent with the white color of well-oxidized $\mathrm{ZnO}(k=\infty)$. However, $\mathrm{ZnO}$ sintered at $1400^{\circ} \mathrm{C}$ (the same temperature used to process the homologous compounds) was black and had a conductivity of $\sim 10 \mathrm{~S} / \mathrm{cm}$, indicating considerable reduction. From this observation, we conclude that, al- 

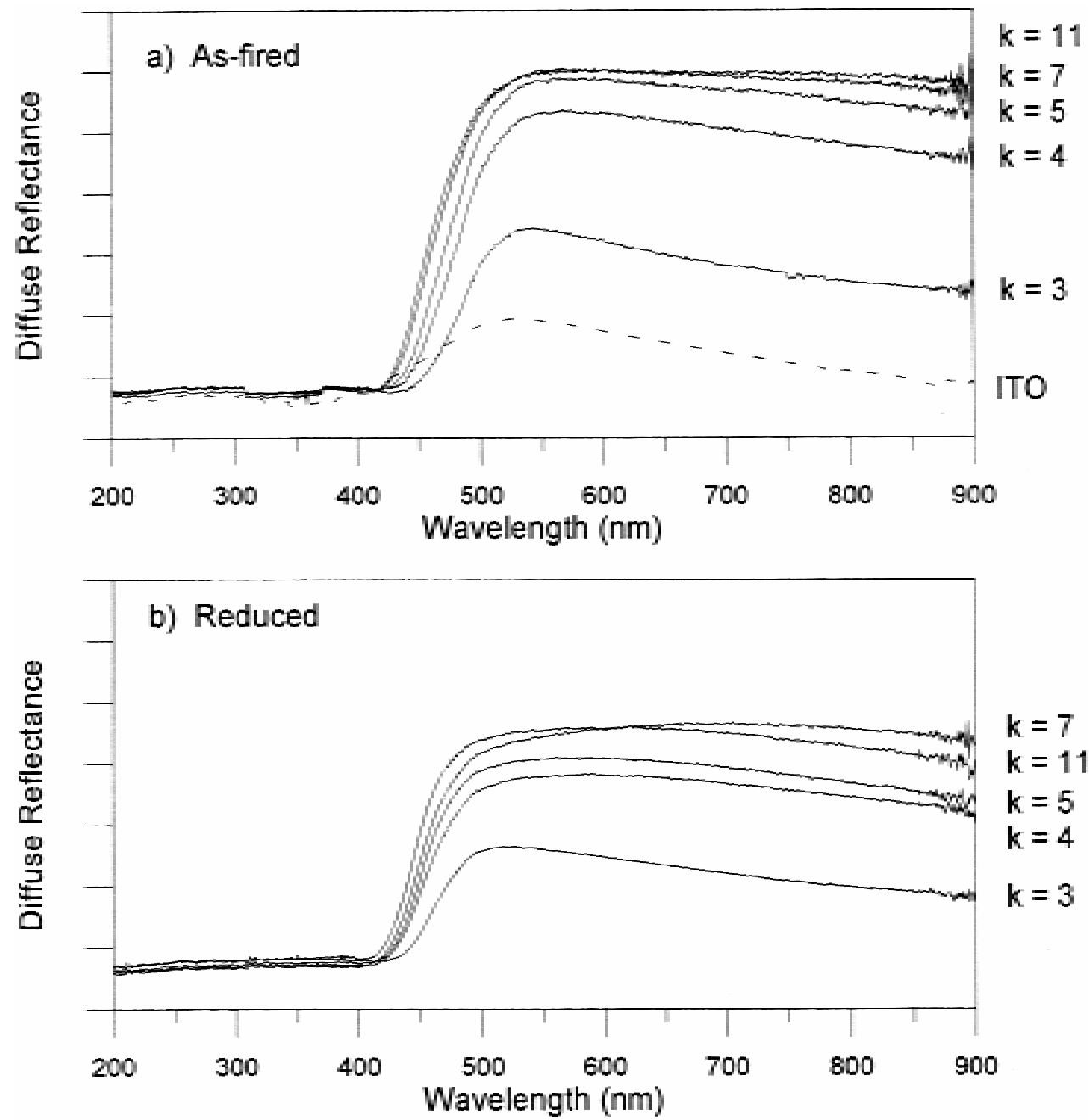

Fig. 5. Diffuse-reflectance spectra for $\mathrm{Zn}_{k} \operatorname{In}_{2} \mathrm{O}_{k+3}\left(k=3,4,5,7\right.$, and 11) compounds and ITO (3\% tin) ((a) after firing at $1400^{\circ} \mathrm{C}$ and $(\mathrm{b})$ after reduction in forming gas at $400^{\circ} \mathrm{C}$ ).

Table III. Electrical and Optical Properties of Select $\mathrm{Zn}_{k} \operatorname{In}_{2} \mathrm{O}_{k+3}$ Compounds

\begin{tabular}{|c|c|c|c|c|c|c|}
\hline \multirow{2}{*}{$\begin{array}{c}k \text { value in } \\
\mathrm{Zn}_{k} \operatorname{In}_{2} \mathrm{O}_{k+3}\end{array}$} & \multicolumn{2}{|c|}{ Absorption-edge $\lambda(\mathrm{nm})$} & \multicolumn{2}{|c|}{ Conductivity, $\sigma(\mathrm{S} / \mathrm{cm})$} & \multirow{2}{*}{$\begin{array}{c}\text { Mobility, } \\
\mu \text { (reduced) } \\
\left(\mathrm{cm}^{2} \cdot(\mathrm{V} \cdot \mathrm{s})^{-1}\right)\end{array}$} & \multirow{2}{*}{$\begin{array}{c}n \text { (reduced) } \\
\left(\times 10^{19} \mathrm{~cm}^{-3}\right) \\
\end{array}$} \\
\hline & As-fired & Reduced & As-fired & Reduced & & \\
\hline 3 & 442 & 437 & 120 & 270 & 25.1 & 6.63 \\
\hline 4 & 435 & 420 & 6.0 & 100 & 13.7 & 4.65 \\
\hline 5 & 432 & 418 & 0.9 & 53 & 12.2 & 2.75 \\
\hline 7 & 423 & 415 & 0.1 & 19 & 11.3 & 1.83 \\
\hline 11 & 420 & 410 & & 6.7 & 4.5 & 0.93 \\
\hline
\end{tabular}

though the higher-order $\mathrm{Zn}_{k} \mathrm{In}_{2} \mathrm{O}_{k+3}$ are believed to contain a considerable volume fraction of $\mathrm{ZnO}$-like layers, their susceptibility to reduction at high temperature and ambient atmosphere is lower than that of $\mathrm{ZnO}$. A porous $\mathrm{ZnO}$ pellet, sintered at $800^{\circ} \mathrm{C}$, was white and insulating, consistent with trends observed for the higher- $k$ members of the homologous series (see Fig. 6). However, a significant increase in the conductivity of $\mathrm{ZnO}$ was not observed after reduction, as was the case for $\mathrm{Zn}_{11} \mathrm{In}_{2} \mathrm{O}_{14}$, the highest-order member of the series studied. Continued efforts are underway to understand the defect chemistry of the $\mathrm{Zn}_{k} \operatorname{In}_{2} \mathrm{O}_{k+3}$ compounds, in terms of the layered structure model and the parent compounds.

The results of this work provide some insight for developing TCOs based on the $\mathrm{Zn}_{k} \mathrm{In}_{2} \mathrm{O}_{k+3}$ compounds. Although the optical properties desired for TCO applications improve with increasing $k$, the electrical properties desired for TCO applications improve with decreasing $k$. Nevertheless, as shown in Fig.
5, all the homologous compounds examined are superior to bulk ITO $\left(3 \%\right.$ tin, processed at $\left.1250^{\circ} \mathrm{C}\right)$ insofar as diffuse reflectance (transmittance) is concerned. Of the compounds examined, $\mathrm{Zn}_{3} \mathrm{In}_{2} \mathrm{O}_{6}$ has the highest conductivity, which is an order of magnitude lower than that desired for TCO applications. Hall measurements indicate that this results from a low carrier concentration rather than a low mobility, e.g., the values measured for $\mathrm{Zn}_{3} \mathrm{In}_{2} \mathrm{O}_{6}\left(6.7 \times 10^{19} \mathrm{~cm}^{-3}\right.$ and $25.1 \mathrm{~cm}^{2} \cdot(\mathrm{V} \cdot \mathrm{s})^{-1}$, respectively) versus the values reported for commercial TCO thin films $\left(6.6 \times 10^{20}-1.2 \times 10^{21} \mathrm{~cm}^{3}\right.$ and $10.2-28.3 \mathrm{~cm}^{2}$. $(\mathrm{V} \cdot \mathrm{s})^{-1}$, respectively). ${ }^{1}$ Excluding $\mathrm{In}_{2} \mathrm{O}_{3}$ from consideration, the increase in conductivity with decreased $k$ suggests that lower-order members of the series, $\mathrm{Zn}_{k} \operatorname{In}_{2} \mathrm{O}_{k+3}(k=1$ and 2), may have higher conductivities than that of $\mathrm{Zn}_{3} \mathrm{In}_{2} \mathrm{O}_{6}$. Although $\mathrm{Zn}_{2} \mathrm{In}_{2} \mathrm{O}_{5}$ has been reported to form at $>1550^{\circ} \mathrm{C}^{6}$ and has been observed in thin-film studies, ${ }^{3,4}$ the formation of $\mathrm{ZnIn}_{2} \mathrm{O}_{4}$ has not been reported. Strategies to increase the con- 


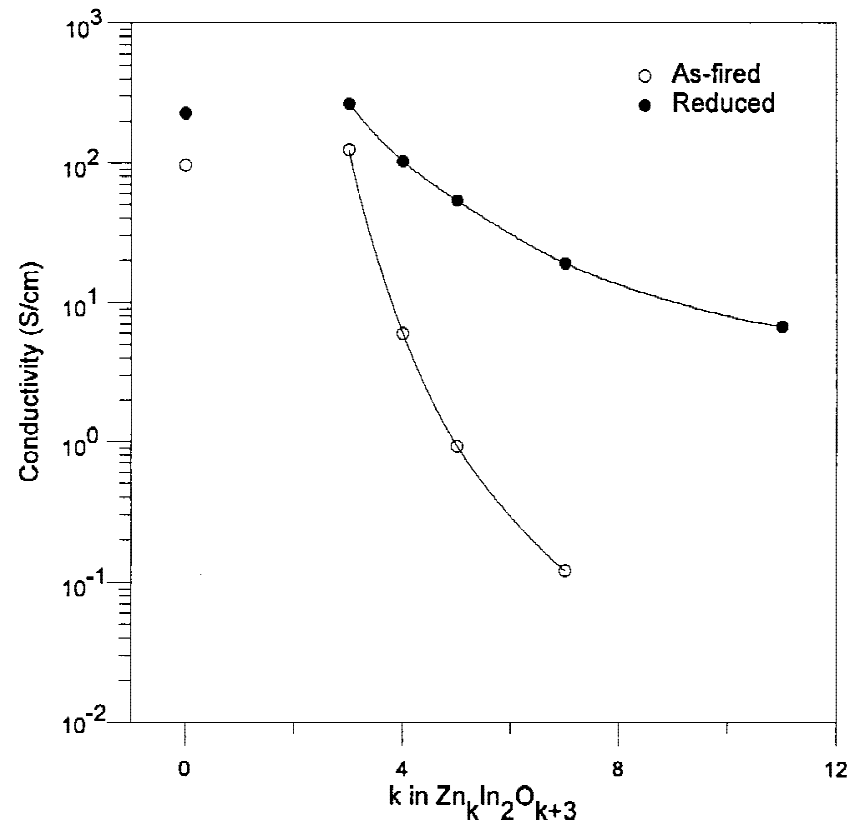

Fig. 6. Room-temperature electrical conductivity before and after reduction in forming gas $\left(4 \% \mathrm{H}_{2}-96 \% \mathrm{~N}_{2}\right)$.

ductivity of the $\mathrm{Zn}_{k} \mathrm{In}_{2} \mathrm{O}_{k+3}$ compounds (stabilization of lower- $k$ members, doping with aliovalent cations, and optimized annealing conditions) are currently being explored.

\section{Conclusions}

The subsolidus phase diagram for the $\mathrm{ZnO}-\mathrm{In}_{2} \mathrm{O}_{3}$ system over the temperature range of $1100^{\circ}-1400^{\circ} \mathrm{C}$ was presented. In addition to $\mathrm{In}_{2} \mathrm{O}_{3}$ and $\mathrm{ZnO}$, nine homologous compounds were observed- $\mathrm{Zn}_{k} \operatorname{In}_{2} \mathrm{O}_{k+3}$, where $k=3,4,5,6,7,9,11,13$, and 15. At $1100^{\circ} \mathrm{C}, \mathrm{Zn}_{5} \mathrm{In}_{2} \mathrm{O}_{8}$ and $\mathrm{Zn}_{7} \mathrm{In}_{2} \mathrm{O}_{10}$ were the only stable compounds other than the component oxides; however, the number of stable compounds increased as the temperature increased. Overall, the temperature ranges of stability determined in this study were in fair agreement with the previously reported literature. ${ }^{6-8}$ The major exception was that the $k=8$ or $k=10$ members of the series were not observed over the temperature range studied.
Trends in electrical conductivity and optical transparency, as functions of $k$ in $\mathrm{Zn}_{k} \operatorname{In}_{2} \mathrm{O}_{k+3}$, were identified. The electrical conductivity increased as $k$ decreased, as a result of increased carrier concentration as well as increased carrier mobility. For all the compounds examined, reduction in forming gas resulted in increased conductivity; however, the magnitude of the effect increased as $k$ increased. The optical band gap and transparency in the visible region increased as $k$ increased. Reduction in forming gas resulted in decreased transparency and a widening of the band gap (the Burstein-Moss shift).

\section{References}

${ }^{1}$ N. R. Lyman, "Transparent Electronic Conductors"; pp. 201-31 in Proceedings of the Symposium on Electrochromic Materials, Electrochemical Society Proceedings, Vols. 90-92. Electrochemical Society, Princeton, NJ, 1990.

${ }^{2}$ R. Wang, L. H. L. King, and A. W. Sleight, "Highly Conducting Transparent Thin Films Based on Zinc Oxide," J. Mater. Res., 11 [7] 1659-64 (1996).

${ }^{3}$ T. Minami, T. Kakumu, and S. Tanaka, 'Preparation of Transparent and Conductive $\mathrm{In}_{2} \mathrm{O}_{3}-\mathrm{ZnO}$ Films by Radio Frequency Magnetron Sputtering,' $J$ Vac. Sci. Technol., A, 14 [3] 1704-708 (1996).

${ }^{4}$ T. Minami, H. Sonohara, T. Kakumu, and S. Tanaka, "Highly Transparent and Conductive $\mathrm{Zn}_{2} \mathrm{In}_{2} \mathrm{O}_{5}$ Thin Films Prepared by RF Magnetron Sputtering," Jpn. J. Appl. Phys., Part 2, 34 [8A] L971-L974 (1995).

5 J. M. Phillips, R. J. Cava, G. A. Thomas, S. A. Carter, J. Kwo, T. Siegrist, J. J. Krajewski, J. H. Marshall, W. F. Peck Jr., and D. H. Rapkine, 'ZincIndium-Oxide: A High Conductivity Transparent Conducting Oxide,' Appl. Phys. Lett., 67 [15] 2246-48 (1994).

${ }^{6}$ V. H. Kasper, "Neuartige Phasen mit Wurtzitahnlichen Strukturn im System $\mathrm{ZnO}-\mathrm{In}_{2} \mathrm{O}_{3}$,'” Z. Anorg. Allg. Chem., 349 [3-4] 113-224 (1967).

${ }^{7}$ N. Nakamura, M. Kimizuka, and T. Mohri, "The Phase Relation in the $\mathrm{In}_{2} \mathrm{O}_{3}-\mathrm{Fe}_{2} \mathrm{ZnO}_{4}-\mathrm{ZnO}$ System at $1350^{\circ} \mathrm{C},{ }^{\prime} J$. Solid State Chem., 86, 16-40 (1990).

${ }^{8}$ N. Kimizuka, M. Isobe, and M. Nakamura, "Synthesis and Single-Crystal Data of Homologous Compounds, $\operatorname{In}_{2} \mathrm{O}_{3}(\mathrm{ZnO})_{m}(m=3,4$, and 5), $\mathrm{InGaO}_{3}(\mathrm{ZnO})_{3}$, and $\mathrm{Ga}_{2} \mathrm{O}_{3}(\mathrm{ZnO})_{m}\left(m=7,8,9\right.$, and 16) in the $\mathrm{In}_{2} \mathrm{O}_{3}$ $\mathrm{ZnGa}_{2} \mathrm{O}_{4}-\mathrm{ZnO}$ System,'’ J. Solid State Chem., 116, 170-78 (1994).

${ }^{9}$ P. J. Cannard and R. J. D. Tilley, "New Intergrowth Phases in the $\mathrm{ZnO}$ $\mathrm{In}_{2} \mathrm{O}_{3}$ System,' J. Solid State Chem., 73, 418-26 (1988).

${ }^{10}$ R. Wang, A. W. Sleight, R. Platzer, and J. A. Gardner, “Nonstoichiometric Zinc Oxide and Indium-Doped Zinc Oxide: Electrical Conductivity and ${ }^{111} \mathrm{In}$ TDPAC Studies,', J. Solid State Chem., 122, 166-75 (1996).

${ }^{11}$ H. Ohta, W.-S. Seo, and K. Koumoto, "Thermoelectric Properties of Homologous Compounds in the $\mathrm{ZnO}-\mathrm{In}_{2} \mathrm{O}_{3}$ System," J. Am. Ceram. Soc., 79 [8] 2193-96 (1996).

${ }^{12}$ F. M. Smits, "Measurement of Sheet Resistivities with the Four-Point Probe," Bell Syst. Tech. J., 37 [3] 711-18 (1958).

${ }^{13}$ L. A. Bursill and G. G. Stone, "Tunnel and Intergrowth Structures in the Gallia-rich Gallium Titanate System,'’ J. Solid State Chem., 38, 149-57 (1981).

${ }^{14}$ H. G. Hecht, "The Present Status of Diffuse Reflectance Theory"; pp. 1-26 in Modern Aspects of Reflectance Spectroscopy. Edited by W. W. Wendlandt. Plenum Press, New York, 1968.

${ }^{15}$ I. Hamberg and C. G. Granqvist, "Evaporated Sn-doped $\operatorname{In}_{2} \mathrm{O}_{3}$ Films: Basic Optical Properties and Applications to Energy-Efficient Windows," J. Appl. Phys., 60 [11] R123-R160 (1986). 